\title{
PENGGUNAAN BATOK KELAPA SEBAGAI MEDIA ALTERNATIF DALAM PENGGANTIAN CARTRIDGE FILTRATION PADA PROSES PEMISAHAN OIL CONTENT DARI AIR FORMASI
}

\author{
Euis Kusniawati ${ }^{1)}$ \\ 1Program Studi Teknik Analisis Laboratorium Migas Politeknik Akamigas Palembang, 30257, Indonesia \\ Corresponding Author E-mail: euis_kusniawati@yahoo.com
}

\begin{abstract}
Abstrak: Air injeksi adalah air formasi yang ikut terproduksi bersama minyak dan gas dan selanjutnya dikembalikan ke dalam sumur yang berfungsi untuk mengatur tekanan formasi suatu sumur. Untuk itu kualitas air injeksi harus selalu diperhatikan. Sebelum dilakukan injeksi, air formasi biasanya dilakukan treatment terlebih dahulu dalam bentuk penyaringan. Air formasi yang telah melewati wash tank tidak sepenuhnya terbebas dari crude oil, untuk itu diperlukan filtrasi terlebih dahulu sebelum melakukan injeksi. Umumnya, arang dan karbon aktif jenis lainnya biasa digunakan sebagai cartridge filter untuk pemisahan air terproduksi dari crude oil. Namun penggunaan kedua bahan tersebut kurang efisien karena memerlukan waktu yang lama serta biaya yang relative mahal. Penelitian dengan menggunakan batok kelapa ini diharapkan menjadi alternatif penggunaan cartridge filtration air formasi sebagai pengganti arang dan karbon aktif lainnya. Penelitian dilakukan dengan menyiapkan limbah batok kelapa dengan ukuran sampel berupa sampel 1 (Halus dengan mess 40), sampel 2 (Sedang dengan mess 30), sampel 3 (Kasar dengan mess 20), sampel 4 (Halus-Sedang), sampel 5 (Halus-Kasar) dan Sampel 6 (Sedang-Kasar). Kemudian dilakukan uji filtrasi menggunakan air terproduksi yang masih mengandung oil content. Selanjutnya dilakukan analisis terhadap sampel air formasi sebelum dan setelah dilakukan filtrasi dengan menggunakan media filtrasi air formasi dengan cartridge filter dari batok kelapa dengan masing-masing ukuran. Sampel dianalisis dengan menggunakan parameter kecepatan laju alir, sedimen dan oil content, dan kapasitas penyerapan. Hasil penelitian ditentukan berdasarkan scorring terhadap masing-masing sampel, dan yang diambil adalah sampel dengan score yang paling tinggi. Berdasarkan scorring didapatkan score berdasarkan urutan sampel sebagai berikut: sampel 1 score 14, sampel 2 score 11, sampel 3 score 14, sampel 4 score 15, sampel 5 score 15 dan sampel 6 score 16. Sehingga score terbaik ada pada sampel 6 dengan komposisi sampel sedang-kasar.
\end{abstract}

Kata Kunci : Batok Kelapa, Air Formasi, Oil Content

\section{PENDAHULUAN}

Menurut Kementerian Energi dan Sumber Daya Mineral (ESDM), pada awal kuartal IV tahun 2017 menunjukkan produksi minyak di Indonesia mencapai 812.083 barrel per hari (Anonim, 2017). Dengan produksi yang terbilang besar itu pastilah melalui proses produksi terlebih dahulu, dimulai dari sumur produksi hingga pemasaran. Dalam produksinya, minyak yang terambil dari sumur produksi tidak sepenuhnya merupakan minyak mentah. Tetapi ada air asin yang ada di dalam formasi reservoir tempat terdapatnya minyak disebut sebagai air formasi. Air formasi merupakan air asin yang ikut terangkat ke atas permukaan bersamaan dengan minyak. Setelah diangkat ke permukaan, air formasi nantinya dipisahkan dari minyak untuk kemudian diinjeksikan menggunakan pompa yang dinamakan injection pump menuju sumur injeksi (well injection) yang tidak jauh dari sumur produksi.

Dalam proes pemisahan ini pada umumnya akan terbentuk emulsi. Emulsi merupakan suatu cairan baru yang terbentuk dari dua fasa cairan yang tidak saling larut yang bercampur sehingga membutuhkan metode dan waktu yang lama untuk memisahkannya. Emulsi ini biasa terjadi pada proses pemurnian air terhadap minyak di Water Treating Plant (WTP) industri eksplorasi minyak bumi. Emulsi yang terbentuk pada proses tersebut adalah emulsi minyak di dalam air, dimana butiran minyak terjebak atau terperangkap didalam butiran air sehingga mempengaruhi kualitas air dimurnikan dari minyak.

Salah satu metode yang digunakan untuk menanggulangi emulsi yang terbentuk dari butiran minyak didalam air adalah dengan 
penyaringan (filtration). Metode penyaringan ini bekerja dengan cara melewatkan umpan (padatan + cairan) melalui medium penyaring. Untuk semua proses filtrasi, umpan mengalir disebabkan adanya tenaga dorong berupa beda tekanan, sebagai contoh adalah akibat gravitasi atau tenaga putar. Secara umum filtrasi dilakukan bila jumlah padatan dalam suspensi relatif lebih kecil dibandingkan zat cairnya.

Mengacu pada Keputusan Menteri Negara Lingkungan Hidup No. 42 tahun 1996 yang menyebutkan bahwa kualitas air yang terkontaminasi minyak pada proses industri dan dapat dibuang ke lingkungan adalah maksimal $25 \mathrm{ppm}$. Kondisi yang sering terjadi pada proses pemurniaan air di Water Treating Plant (WTP) adalah ketidakstabilan pencapaian kualitas air yang terkontaminasi minyak dari proses produksi yang berkisar 20 ppm sampai 40 ppm.

Masalah yang terjadi ini perlu dicari solusinya, karena telah menjadi masalah di Water Treating Plant (WTP) yang berujung pada produktivitas industri hulu minyak bumi dalam menghasilkan produk berupa minyak bumi mentah. Oleh karena itu, masalah ini menjadikan dasar dilakukannya penelitian pada beberapa variable dalam pembuatan cartridge filtration yang berasal dari tempurung kelapa.

Beberapa penelitian sebelumnya yang pernah dilakukan untuk mengatasi oil content pada air formasi, yaitu penelitian yang dilakukan oleh Noor Al-Jamal dan Tatjana Juzsakova pada tahun 2016 dengan judul Review on the effectiveness of adsorbent materials in oil spill clean up. Pada penelitiannya ini Noor Al Jamal dan Tatjana melakukan pemisahan oil content dengan menggunakan metode filtrasi menggunakan adsorben yang berasal dari carbon (CNT). Selain itu penelitian mengenai oil content juga dilakukan oleh Augustine Osamor Ifelebuegu dan Zenebu Momoh pada tahun 2015 dengan judul An Evaluation of the Adsorptive Properties of Coconut Husk for Oil Spill Cleanup. Pada penelitiannya Augustine menggunakan sabut kelapa sebagai adsorben untuk membersihkan minyak dan solar yang terdapat pada air laut. Dari penelitian ini dapat disimpulkan bahwa sabut kelapa cukup efektif untuk menyerap minyak dan solar yang terdapat pada air laut.

Penelitian megenai tempurung kelapa juga dilakukan oleh Neng Mastiani, Vina Amalia, Tina Dewi Rosahdi pada tahun 2018. Pada penelitiannya Mastiani dkk mengambil judul Potensi Penggunaan Tempurung Kelapa sebagai Adsorben Ion Logam $\mathrm{Fe}$ (III). Berdasarkan hasil penelitian, tempurung kelapa efektif digunakan sebagai adsorben untuk penurunan logam besi pada larutan $\mathrm{Fe}(\mathrm{III})$. Penelitian mengenai tempurung kelapa lainnya dilakukan oleh Lucia Hermawati Rahayu, Sari Purnavita dan Herman Yoseph Sriyana pada tahun 2014. Penelitian yang berjudul potensi sabut dan tempurung kelapa sebagai adsorben untuk meregenerasi minyak jelantah. Hasil penelitian menunjukkan bahwa sabut dan tempurung kelapa pada berbagai metode perlakuan awal dapat mengurangi kadar FFA, PV, dan warna minyak goreng bekas.

Berdasarkan beberapa penelitian diatas, maka kami bermaksud melakukan penelitian mengenai pemisahan oil content dari air formasi menggunakan cartridge filter yang berasal dari tempurung kelapa.

\section{TEORI DASAR}

\subsection{Air Formasi}

Air formasi disebut pula dengan oil field water atau connate water atau interstitial water, yaitu air yang terproduksi bersamasama dengan minyak dan gas, karena adanya gaya dorong dari air (water drive) yang mengisi pori-pori yang ditinggalkan minyak. Air formasi hampir selalu ditemukan di dalam reservoir hidrokarbon. Air formasi diperkirakan berasal dari laut yang ikut terendapkan bersama dengan endapan sekelilingnya, karena situasi pengendapan batuan reservoir minyak terjadi pada lingkungan pengendapan laut. Air formasi hampir selalu ditemukan di dalam reservoir hidrokarbon karena memang dengan adanya air ini ikut menentukan terakumulasinya hidrokarbon didalam suatu akumulasi minyak, 
air selalu menempati sebagian dari suatu reservoir, minimal $10 \%$ dan maksimal $100 \%$ dari keseluruhan pori.

\subsubsection{Sifat Fisik Air Formasi}

\section{Densitas $(\rho)$}

Densitas ( $\rho)$ adalah massa air murni pada suatu reservoir dinyatakan dengan massa per satuan volume, specifik volume yang dinyatakan dalam persatuan massa dan specific gravity yaitu densitas air formasi pada suatu kondisi tertentu, yaitu pada tekanan 14,7 psi dan temperatur $60{ }^{\circ} \mathrm{F}$. Berat jenis $(\rho)$ pada reservoir dapat ditentukan dengan membagi $\rho w$ pada kondisi atandart dengan faktor volume formasi $(\mathrm{Bw})$ dan perhitungan itu dapat dilakukan bila air formasi jenuh terhadap gas alam pada kondisi reservoir

\section{Viskositas $(\mu)$}

Viskositas $(\mu)$ akan tergantung pada tekanan, temperatur dan tingkat salinitas yang dikandung air formasi tersebut. Viskositas $(\mu)$ akan naik terhadap turunnya temperatur dan kenaikan tekanan. Kegunaan mengenai perilaku kekentalan air formasi pada kondisi reservoir terutama untuk mengontrol gerakan air formasi di dalam reservoir

3. Faktor volume formasi air formasi (B)

Faktor volume formasi

menunjukkan perubahan volume air formasi dari kondisi permukaan. Faktor volume formasi air formasi ini dipengaruhi oleh pembebasan gas dan air dengan turunnya tekanan, pengembangan air dengan turunnya tekanan dan penyusutan air dengan turunnya suhu.

\section{Kompressibilitas (C)}

Kompressibilitas (C) didefinisikan sebagai perubahan volume air formasi yang disebabkan oleh adanya perubahan tekanan yang mempengaruhinya. Kompressibilitas air murni tergantung pada suhu, tekanan, dan kelarutan gas dalam air.

\section{Kelarutan gas dalam air formasi}

Kelarutan gas dalam air formasi akan lebih kecil bila dibandingkan dengan kelarutan gas dalam minyak di reservoir pada tekanan dan temperatur yang sama.

\subsubsection{Sifat Kimia Air Formasi}

Sifat kimia Air formasi memiliki dua sifat yaitu asam dan basa. Sifat asam mengakibatkan korosi. Korosi adalah pengkaratan. Hal ini dapat menyebabkan pemproduksian minyak terganggu. Bila air formasi yang bersifat asam tetap di alirkan maka dapat merusak pipa. Hal ini disebabkan air yang melekat di pipa-pipa yang semakin lama semakin mengeras dan mengakibatkan pengkaratan

Sedangkan sifat air formasi yang basa, mengakibatkan terjadinya endapan. Endapan dapat berbentuk pasir dan sedimen. Endapan dapat dihancurkan menggunakan demulsifier. Endapan sendiri dapat mengakibatkan merusak produksi minyak yang dihasilkan. Dalam artian minyak yang mengandung endapan akan memperburuk minyak yang dihasilkan. Kandungan utama dalam air formasi ini adalah unsur $\mathrm{K}$ (kalium) dan $\mathrm{Cl}$ (chlor) dijumpai dalam jumlah yang sangat banyak. .

\subsection{Minyak Bumi (Crude Oil)}

Minyak bumi disebut petroleum dalam bahasa inggris, dari bahasa latin petrus yang artinya karang dan oleum berarti minyak. Minyak bumi dijuluki juga sebagai emas yang hitam adalah cairan kental, berwarna coklat gelap, atau kehijauan yang mudah terbakar, yang berada di lapisan atas dari beberapa area di kerak bumi. Minyak bumi terdiri dari campuran kompleks dari berbagai hidrokarbon, sebagian besar seri alkana, tetapi bervariasi dalam penampilan, komposisi, dan kemurniannya.

\subsubsection{Proses Pembentukan Minyak Mentah}

Minyak bumi adalah hasil dari peruraian (dekomposisi) materi tumbuhan dan hewan di suatu daerah yang subsidence (turun) secara perlahan. Daerah tersebut biasanya berupa laut batas lagoon (danau) sepanjang pantai ataupun danau dan rawa di daratan. Sedimen diendapkan bersama-sama dengan materi tersebut dan kecepatan pengendapan sedimen harus cukup cepat sehingga paling tidak bagian materi organik tersebut dapat tersimpan dan tertimbun dengan baik sebelum terjadi pembusukan. Pada kondisi sirkulasi dan reduksi tertentu akumulasi hidrokarbon banyak ditemukan pada bagian air laut dalam. 


\subsubsection{Komposisi Kimia Minyak Mentah}

Minyak bumi hanya berisi minyak mentah saja, tetapi dalam penggunaan seharihari ternyata juga digunakan dalam bentuk hidrokarbon padat, cair, dan gas lainnya. Pada kondisi temperatur dan tekanan standar, hidrokarbon yang ringan seperti metana, etana, propana, dan butana berbentuk gas yang mendidih pada $-161,6{ }^{\circ} \mathrm{C},-88,6{ }^{\circ} \mathrm{C},-42{ }^{\circ} \mathrm{C}$, dan $-0,5^{\circ} \mathrm{C}$, berturut-turut $\left(-258,9^{\circ},-127,5^{\circ}\right.$, $43,6^{\circ}$, dan $+31,1^{\circ} \mathrm{F}$ ), sedangkan karbon yang lebih tinggi, mulai dari pentana ke atas berbentuk padatan atau cairan. Meskipun begitu, di sumber minyak di bawah tanah, proporsi gas, cairan, dan padatan tergantung dari kondisi permukaan dan diagram fase dari campuran minyak bumi tersebut.

\section{Tabel 2.1 Persentase Kandungan Elemen Unsur pada Crude Oil}

\begin{tabular}{|l|c|}
\hline \multicolumn{1}{|c|}{ Elemen } & Rentang Persentase \\
\hline Karbon & $83-87 \%$ \\
\hline Hidrogen & $10-14 \%$ \\
\hline Nitrogen & $0,1-2 \%$ \\
\hline Oksigen & $0,05-1,5 \%$ \\
\hline Sulfur & $0,05-6,0 \%$ \\
\hline Logam & $<0,1 \%$ \\
\hline
\end{tabular}

Sumber : Hardoko IQ. 2006

Tabel 2.2 Komposisi Molekul Berdasarkan Berat

\begin{tabular}{|l|c|c|}
\hline Hidrokarbon & Rata-rata & Rentang \\
\hline Parafin & $30 \%$ & $15-60 \%$ \\
\hline Naptena & $49 \%$ & $30-60 \%$ \\
\hline Aromatik & $15 \%$ & $3-30 \%$ \\
\hline Aspaltena & $6 \%$ & sisa-sisa \\
\hline
\end{tabular}

Sumber: Hardoko IQ. 2006

Penampakan fisik dari minyak bumi sangatlah beragam tergantung dari komposisinya. Minyak bumi biasanya berwarna hitam atau coklat gelap (meskipun warnanya juga bisa kekuningan, kemerahan, atau bahkan kehijauan). Pada sumur minyak biasanya ditemukan juga gas alam yang mempunyai massa jenis lebih ringan daripada minyak bumi, sehingga biasanya keluar terlebih dahulu dibandingkan minyak. Dalam campuran itu, terdapat juga air asin, yang massa jenisnya lebih rendah sehingga berada di lapisan bawah minyak.

\subsection{Adsorbsi}

\subsubsection{Adsorbsi Fisika}

Adsorbsi fisika Berhubungan dengan gaya Van Der Waals. Apabila daya tarik menarik antara zat terlarut dengan adsorben lebih besar dari daya tarik menarik antara zat terlarut dengan pelarutnya, maka zat yang terlarut akan diadsorbsi pada permukaan adsorben. Adsorbsi ini mirip dengan proses kondensasi dan biasanya terjadi pada temperatur rendah. Pada proses ini gaya yang menahan molekul fluida pada permukaan solid relatif lemah, dan besarnya sama dengan gaya kohesi molekul pada fase cair (gaya Van Der Waals) mempunyai derajat yang sama dengan panas kondensasi dari gas menjadi cair, yaitu sekitar 2,19-21,9 kg/mol. Keseimbangan antara permukaan solid dengan molekul fluida biasanya cepat tercapai dan bersifat reversibel. Adsorbsi dapat memurnikan suatu larutan dari zat-zat pengotornya.

\subsubsection{Adsorbsi Kimia}

Adsorbsi kimia yaitu reaksi yang terjadi antara zat padat dengan zat terlarut yang teradsorbsi. Adsorbsi ini bersifat spesifik dan melibatkan gaya yang jauh lebih besar daripada adsorbsi fisika. Panas yang dilibatkan adalah sama dengan panas reaksi kimia. Menurut Langmuir, molekul teradsorbsi ditahan pada permukaan oleh gaya valensi yang tipenya sama dengan yang terjadi antara atom- atom dalam molekul. Karena adanya ikatan kimia maka pada permukaan adsorben akan terbentuk suatu lapisan. Terbentuknya lapisan tersebut akan menghambat proses penyerapan selanjutnya oleh bantuan adsorben sehingga efektifitasnya berkurang.

\subsection{Oil Content}

Oil content adalah kandungan minyak sisa yang terikut pada air formasi yang akan di injeksikan kedalam sumur injeksi. Oil Content ini sangat berdampak sekali apabila tidak ditanggulangi karena pada saat penginjeksian air formasi tersebut menggunakan pompa 
injeksi. Sedangkan kandungan minyak tersebut tidak boleh ikut ter injeksi bersama air formasi karena dapat merusak pompa tersebut. (Alaert,. G, 1987)

Sedangkan baku mutu yang mengatur batasan maksimal konsentrasi minyak yang diperbolehkan untuk air limbah salah satunya ditetapkan dalam Perda No. 5 Tahun 2012. Kisaran konsentrasi yang disyaratkan adalah 2-25 mg/L. Baku mutu Kepmen LH No.51 tahun 2004 juga telah menetapkan konsentrasi maksimum untuk air permukaan dan laut. Konsentrasi maksimal yang dibolehkan lebih kecil dari effluent air limbah industri, yaitu 1 $\mathrm{mg} / \mathrm{L}$. Perairan lain seperti air laut pada perairan pelabuhan dipersyaratkan mempunya ikonsentrasi minyak dan lemak maximum sebesar $5 \mathrm{mg} / \mathrm{L}$.

\subsection{Cartridge Filter}

Cartridge filter adalah suatu alat yang dipergunakan sebagai media penyaring atau pemisahan pada air yang biasa digunakan untuk memisahkan air dari partikel-partikel lainnya. Sedangkan pada penelitian ini cartridge filter digantikan dengan batok kelapa dikarenakan batok kelapa merupakan suatu limbah yang mempunyai sifat adsorbsi terhadap minyak dan batok kelapa tersebut sangat mudah didapatkan.

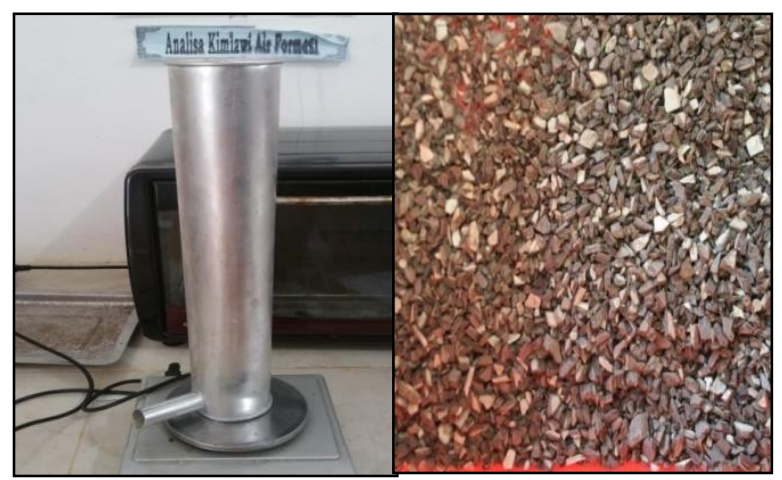

(a)

(b)

Gambar 2.1 (a) Cartridge Filter, (b) Bahan Pengganti Filtrasi

Pada penelitian kali ini, peneliti hendak menggunakan bahan filtrasi yang terdapat pada cartridge yang berasal dari batok kelapa, biasanya bahan yang digunakan sebagai isian untuk cartridge filter ini berasal dari arang atau karbon aktif jenis lainnya. Pada penelitian awal ini peneliti ingin mengetahui ukuran (mess) yang tepat dari batok kelapa untuk menghasilkan penyerapan oil content yang optimal dari air formasi.

\subsection{Kelapa}

Kelapa (Cocos nucifera) adalah anggota tunggal dalam marga Cocos dari suku aren-arenan atau Arecaceae. Tumbuhan ini dimanfaatkan hampir semua bagiannya oleh manusia sehingga dianggap sebagai tumbuhan serbaguna, terutama bagi masyarakat pesisir. Kelapa juga adalah sebutan untuk buah yang dihasilkan tumbuhan ini.

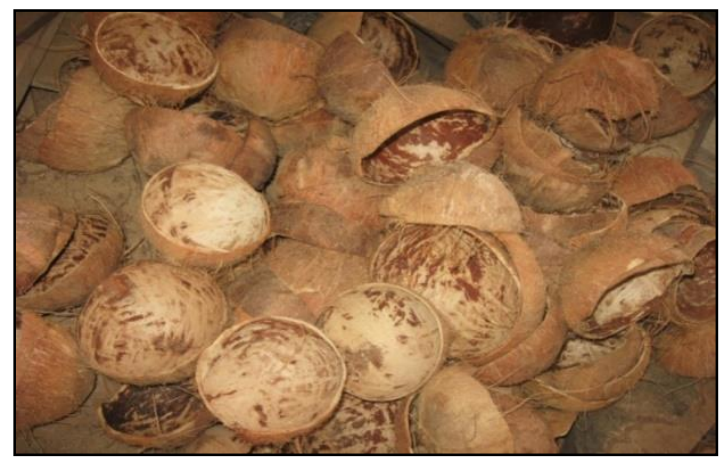

Gambar 2.3 Tempurung Kelapa

Pohon kelapa merupakan pohon yang multifungsi, karena semua bagiannya dapat dimanfaatkan. Pada penelitian ini memanfaatkan tempurung kelapa. yang dihancurkan. Tempurung merupakan lapisan keras yang terdiri atas lignin, selulosa, metoksil, dan berbagai mineral. Kandungan bahan-bahan tersebut beragam sesuai dengan jenis kelapanya. Struktur yang keras disebabkan oleh silikat $\left(\mathrm{SiO}_{2}\right)$ yang cukup tinggi kadarnya pada tempurung. Berat tempurung sekitar $15-19 \%$ dari berat keseluruhan.

Tabel 2.3 Kemampuan Tempurung Kelapa Menyerap Logam

\begin{tabular}{|c|c|c|c|}
\hline Adsorben & $\begin{array}{l}\mathrm{Pb} \\
(\mathrm{mg})\end{array}$ & $\begin{array}{l}\mathrm{Fe} \\
(\mathrm{mg})\end{array}$ & $\begin{array}{l}\mathrm{Cu} \\
(\mathrm{mg})\end{array}$ \\
\hline 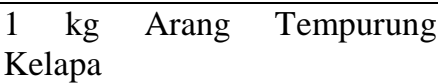 & 35,8 & 15,5 & 13,8 \\
\hline $\begin{array}{lcc}1 & \text { kg Arang } & \text { Tempurung } \\
\text { Kelapa (Aktivasi) } & \end{array}$ & 56,3 & 43,8 & 39,9 \\
\hline $\begin{array}{l}1 \text { kg Arang Tempurung } \\
\text { Kelapa }\left(\text { Aktivasi }+\mathrm{ZnCl}_{2}\right)\end{array}$ & 72,3 & 36,1 & 52,7 \\
\hline
\end{tabular}

Sumber: Hardoko IQ. 2006 
Dari penelitian lain di Universitas Lampung menyebutkan arang tempurung kelapa juga mempunyai kemampuan untuk menyerap logam berat $\mathrm{Pb}, \mathrm{Fe}$, dan $\mathrm{Cu}$ pada tabel 2.3. Dari tabel tersebut secara umum diketahui bahwa arang tempurung kelapa yang paling efektif untuk menyerap logam berat adalah arang yang telah diaktivasi dan ditambahkan $\mathrm{ZnCl}_{2}$. Selain untuk logam berat, arang tempurung kelapa juga baik diterapkan dalam pengolahan limbah air industri.

\section{HASIL DAN PEMBAHASAN}

\subsection{Data Hasil Penelitian}

1. Hasil uji sampel terhadap laju alir fluida

\section{Tabel 3.1 Hasil Uji Laju Alir Fluida}

\begin{tabular}{|c|c|c|c|c|}
\hline $\begin{array}{c}\text { No. } \\
\text { Sampel }\end{array}$ & $\begin{array}{c}\text { Ukuran } \\
\text { Sampel } \\
\text { Batok } \\
\text { Kelapa }\end{array}$ & $\begin{array}{c}\text { Volume } \\
\text { Air } \\
\text { Formasi } \\
(\mathrm{ml})\end{array}$ & $\begin{array}{c}\text { Waktu } \\
(\text { secon })\end{array}$ & $\begin{array}{c}\text { Laju } \\
\text { Alir } \\
(\mathrm{ml} / \mathrm{s})\end{array}$ \\
\hline 1 & Halus & 200 & 97,00 & 2,06 \\
\hline 2 & Sedang & 200 & 39,18 & 5,10 \\
\hline 3 & Kasar & 200 & 27,60 & 7,24 \\
\hline 4 & $\begin{array}{c}\text { Halus } \\
\text { Sedang }\end{array}$ & 200 & 44,11 & 4,53 \\
\hline 5 & $\begin{array}{c}\text { Halus } \\
\text { Kasar }\end{array}$ & 200 & 38,66 & 5,17 \\
\hline 6 & $\begin{array}{c}\text { Sedang } \\
\text { Kasar }\end{array}$ & 200 & 29,18 & 6,85 \\
\hline
\end{tabular}

2. Hasil uji sampel terhadap kapasitas penyerapan batok kelapa

Tabel 3.2 Hasil Uji Berdasarkan Kapasitas Penyerapan Batok Kelapa

\begin{tabular}{|c|c|c|c|}
\hline $\begin{array}{c}\text { No. } \\
\text { Sampel }\end{array}$ & $\begin{array}{c}\text { Ukuran } \\
\text { Sampel } \\
\text { Batok Kelapa }\end{array}$ & $\begin{array}{c}\text { Massa } \\
\text { sampel } \\
(\mathrm{g})\end{array}$ & $\begin{array}{c}\text { Kapasitas } \\
\text { sampel } \\
(\mathrm{ml})\end{array}$ \\
\hline 1 & Halus & 200 & 600 \\
\hline 2 & Sedang & 200 & 550 \\
\hline 3 & Kasar & 200 & 450 \\
\hline 4 & $\begin{array}{c}\text { Halus } \\
\text { Sedang }\end{array}$ & $\begin{array}{l}100 \\
100 \\
\end{array}$ & 560 \\
\hline 5 & $\begin{array}{l}\text { Halus } \\
\text { Kasar }\end{array}$ & $\begin{array}{l}100 \\
100\end{array}$ & 540 \\
\hline 6 & $\begin{array}{c}\text { Sedang } \\
\text { Kasar }\end{array}$ & $\begin{array}{l}100 \\
100\end{array}$ & 470 \\
\hline
\end{tabular}

3. Hasil uji sampel terhadap kadar air formasi

Tabel 3.3 Hasil Dari Pengujian Kadar Air Formasi

\begin{tabular}{|c|c|c|c|c|c|c|c|c|c|c|c|c|}
\hline \multirow{3}{*}{ 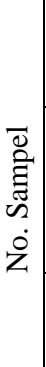 } & \multicolumn{6}{|c|}{ Kondisi Sebelum } & \multicolumn{6}{|c|}{$\begin{array}{c}\text { Kondisi Sesudah } \\
\text { (Rata-rata } 2 \text { sampel } \\
\text { yang diambil) }\end{array}$} \\
\hline & \multicolumn{2}{|c|}{ 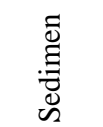 } & \multicolumn{2}{|c|}{$\overline{0}$} & \multicolumn{2}{|c|}{$\begin{array}{l}\dot{\bar{E}} \\
\dot{B}\end{array}$} & \multicolumn{2}{|c|}{ Ðే } & \multicolumn{2}{|c|}{$\overline{0}$} & \multicolumn{2}{|c|}{$\begin{array}{l}\overline{ \pm} \\
\bar{E}\end{array}$} \\
\hline & ฮี & $b^{\circ}$ & శ్ & $b^{0}$ & छ్ర & 8 & हี & $d^{0}$ & ‡్丶 & $d^{2}$ & శ్ర & $d^{2}$ \\
\hline 1 & రె. & กี & ڤ̊ & $\begin{array}{l}\text { テे } \\
\text { ்ָ }\end{array}$ & $\begin{array}{l}n \\
\text { n }\end{array}$ & $\stackrel{\infty}{\stackrel{\infty}{\infty}}$ & $\underset{0}{\stackrel{0}{0}}$ & 8 & రీ & ڤ̊ & $\begin{array}{l}8 \\
\forall\end{array}$ & $\begin{array}{l}\stackrel{2}{n} \\
\infty \\
\infty\end{array}$ \\
\hline 2 & రె. & $\stackrel{n}{2}$ & ڤ̊ & $\begin{array}{l}\text { テे } \\
\text { ป }\end{array}$ & n̊ & $\stackrel{\infty}{\stackrel{\infty}{N}}$ & $\stackrel{8}{0}$ & $\begin{array}{l}\infty \\
0 \\
0\end{array}$ & $\frac{n}{0}$ & $\frac{0}{\stackrel{0}{f}}$ & $\begin{array}{l}\stackrel{\circ}{n} \\
\text { r }\end{array}$ & $\begin{array}{l}\text { ㅇ․ } \\
\text { ปे }\end{array}$ \\
\hline 3 & $\begin{array}{l}0 \\
0\end{array}$ & $\stackrel{n}{2}$ & ڤ̊ & $\begin{array}{r}\text { テे } \\
\text { N }\end{array}$ & $\stackrel{n}{n}$ & $\stackrel{\infty}{\stackrel{\infty}{\infty}}$ & ర్. & ণ్ & $\stackrel{\overbrace{}}{\text { กิ }}$ & $\frac{0}{n}$ & $\frac{\stackrel{R}{r}}{\dot{m}}$ & ๙̊ \\
\hline 4 & $\begin{array}{l}\overline{0} \\
0\end{array}$ & $\stackrel{n}{2}$ & ڤ̊ & $\begin{array}{l}\text { テे } \\
\text { ป }\end{array}$ & $\begin{array}{l}\circ \\
\text { n }\end{array}$ & $\stackrel{\infty}{\stackrel{\infty}{N}}$ & 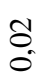 & 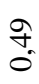 & $\stackrel{n}{0}$ & $\stackrel{\text { ิ }}{-}$ & $\begin{array}{l}8 \\
8 \\
f\end{array}$ & $\begin{array}{l}\stackrel{2}{2} \\
\infty \\
\infty\end{array}$ \\
\hline 5 & $\begin{array}{l}\overline{0} \\
0\end{array}$ & $\stackrel{n}{2}$ & ڤ̊ & $\begin{array}{l}\text { テे } \\
\text { ป̃ }\end{array}$ & $\begin{array}{l}\stackrel{\circ}{n} \\
\text { ri }\end{array}$ & $\stackrel{\infty}{\stackrel{\infty}{N}}$ & Oֵ & $\stackrel{b}{2}$ & $\frac{0}{0}$ & $\begin{array}{l}\stackrel{8}{+} \\
\text { i }\end{array}$ & \begin{tabular}{l}
8 \\
\hdashline \\
+
\end{tabular} & ñ. \\
\hline 6 & $\overline{0}$ & ֶీ & ஜ̊ & $\begin{array}{l}\text { テे } \\
\text { ป̃ }\end{array}$ & $\stackrel{0}{n}$ & $\stackrel{\infty}{\underset{N}{N}}$ & $\overline{0}$ & ָ̊ & $\frac{0}{0}$ & $\begin{array}{l}\text { 尺) } \\
\text { i }\end{array}$ & $\begin{array}{l}\stackrel{一}{\infty} \\
\text { ஸे }\end{array}$ & $\frac{\text { N̦ }}{\hat{n}}$ \\
\hline
\end{tabular}

\subsection{Pembahasan}

Proses separasi minyak yang terjadi pada separator akan menghasilkan crude oil, raw gas dan sejumlah air fomasi. Crude oil yang dihasilkan akan dilanjutkan proses pemurniannya pada wash tank. Sementara air formasi akan diteruskan menuju cartridge filter untuk memisahkan crude oil yang masih terikut pada air formasi, diharapkan melalui proses penyaringan yang terjadi di cartridge filter akan didapatkan air yang siap untuk diinjeksikan ke subsurface. Air yang berasal dari wash tank dan cartridge filter akan dikumpulkan pada water storage tank untuk selanjutnya di-treatment dengan berbagai chemical agar zat yang tidak diharapkan ada pada air formasi dapat diminimalisir keberadaannya. Setelah itu, air formasi yang 
sudah dapat dikategorikan air injeksi dapat diinjeksikan ke sumur-sumur injeksi terdekat. Seringkali ditemukan air injeksi masih mengandung sedikit crude oil (disebut oil content). Hal ini sangat dihindari dalam proses penginjeksian air ke sumur injeksi karena akan berakibat negatif pada peralatan produksi seperti pompa (khususnya pompa sentrifugal) dan pipa, karena peralatan tersebut sangat rentan rusak apabila dialiri fluida dengan fase yang berbeda (air dan minyak).

\subsubsection{Uji Laju Alir Fluida}

Salah satu parameter yang digunakan pada penelitian ini adalah laju alir fluida. uji laju alir fluida ini bertujuan untuk mendapatkan kecepatan alir fluida yang melewati peralatan uji (sampel) yang telah disiapkan. Dalam pelaksanaannya penelitian ini menggunakan beberapa variasi ukuran sampel batok kelapa yang dimasukkan kedalam alat penyaring. Variasi Komposisi dari sampel batok kelapa yang dimasukkan berjumlah 200 gram dengan berbagai ukuran sampel.

Analisis dari parameter ini akan menentukan komposisi sampel mana yang lebih efisien dari beberapa ukuran sampel batok kelapa yang telah disiapkan. Secara teori dapat diketahui bahwa ukuran batok kelapa yang lebih kecil memberikan kecepatan laju alir yang lebih lambat dibandingkan dengan sampel batok kelapa yang ukurannya lebih besar. Berdasarkan data pada tabel 3.1 dilakukan perbandingan antara ukuran sampel batok kelapa terhadap laju alir fluida yang mengalir sesuai pada gambar 3.1.

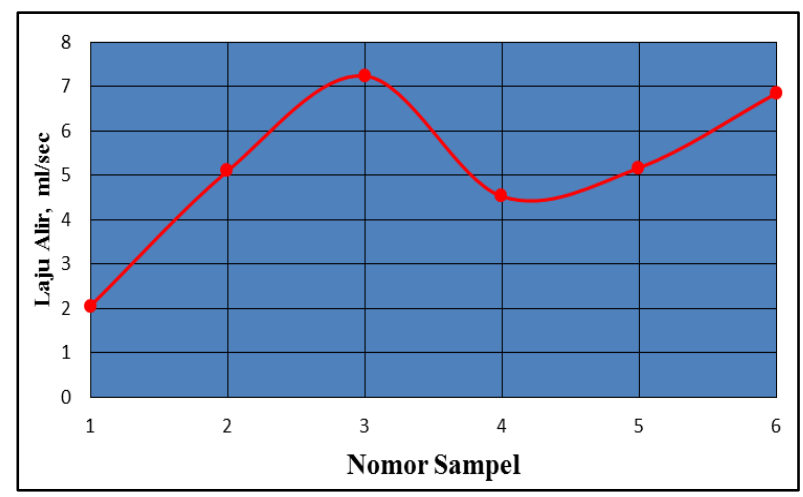

Gambar 3.1 Grafik Laju Alir Fluida Terhadap Sampel
Dari grafik di atas dapat dilihat bahwa sampel nomor 3 (kasar) mampu mengalirkan fluida lebih cepat daripada sampel lainnya, dan sampel nomor 1 (halus) mempunyai kemampuan mengalirkan fluida lebih lambat daripada sampel nonmor lainnya. Hal ini dikarenakan ukuran pori antar butiran batok kelapa pada sampel nomor 1 lebih kecil bila dibandingkan dengan sampel lainnya yaitu 40 mesh. Dari gambar 3.1 dapat dilihat bahwa sampel nomor 3 (kasar) dan 6 (sedang kasar) sangat menguntungkan dari segi waktu penyaringan, hal ini dibuktikan dengan data laju alir fluida yang tinggi berada pada sampel ini. Dari gambar 3.1 juga dapat diketahui ukuran sampel berdasarkan laju alir mulai dari yang tercepat sampai yang terlama adalah sampel dengan ukuran nomor 3 (kasar), 6 (sedang kasar), 5 (halus kasar), 2 ( sedang), 4 (halus sedang), 1 (halus).

\subsubsection{Uji Kapasitas Penyerapan}

Parameter uji kapasitas penyerapan ini bertujuan untuk mendapatkan kapasitas penyerapan dari sampel batok kelapa terhadap oil content yang terdapat pada air formasi dengan ukuran sampel yang bervariasi. untuk mendapatkan hasil dari uji kapasitas penyerapan ini dilakukan dengan menyaring oil content dengan batok kelapa secara bertahap sampai batok kelapa tersebut tidak mampu lagi menyerap oil content. Hasil uji terhadap kapasitas penyerapan dapat dilihat pada tabel 3.2. Berdasarkan data pada tabel 3.2 dilakukan perbandingan antara ukuran sampel batok kelapa terhadap uji kapasitas penyerapan seperti pada gambar 3.2.

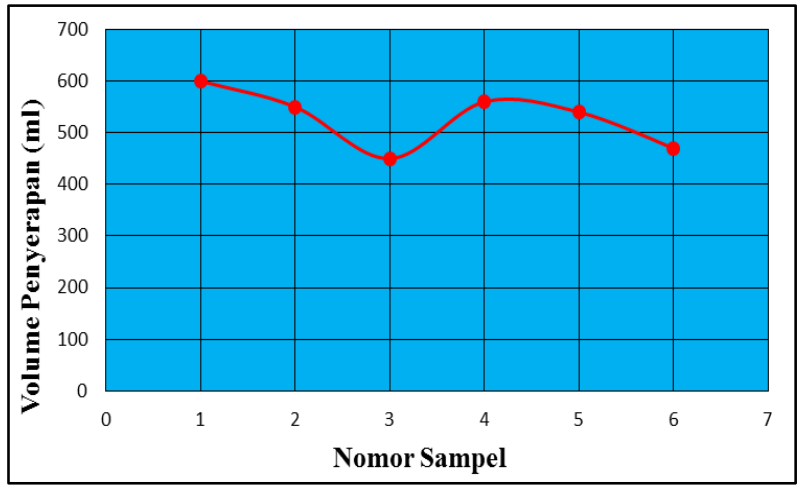

Gambar 3.2 Grafik Kapasitas Penyerapan 
Berdasarkan gambar 3.2 dapat diketahui bahwa sampel nomor 1 (halus) memiliki kapasitas penyerapan yang lebih baik apabila dibandingkan dengan sampel lainnya. Dan sampel nomor 3 (kasar) memiliki kapasitas penyerapan yang tidak baik. Urutan dari pada ukuran sampel berdasarkan kapasitas penyerapannya mulai dari yang paling banyak menyerap sampai yang paling sedikit adalah sampel nomor 1 (halus), 4 (halus sedang), 2 (sedang), 5 (halus kasar), 6 (sedang kasar), 3 (kasar).

\subsubsection{Uji Kandungan Sedimen pada Air Formasi}

Uji kandungan air formasi yang dilakukan bertujuan untuk mengetahui apakah sampel batok kelapa yang digunakan dalam penyaringan ini dapat mempengaruhi kualitas air formasi yang mengandung oil content atau tidak. Analisis terhadap kandungan air formasi dilakukan sebelum dan sesudah penyaringan menggunakan batok kelapa. Hasil yang didapatkan dapat dilihat pada tabel 3.3. Dan setelah dilakukan analisis kandungan air formasi mengenai persentase kandungan sedimen sebelum dan sesudah dapat dilihat pada gambar 3.3.

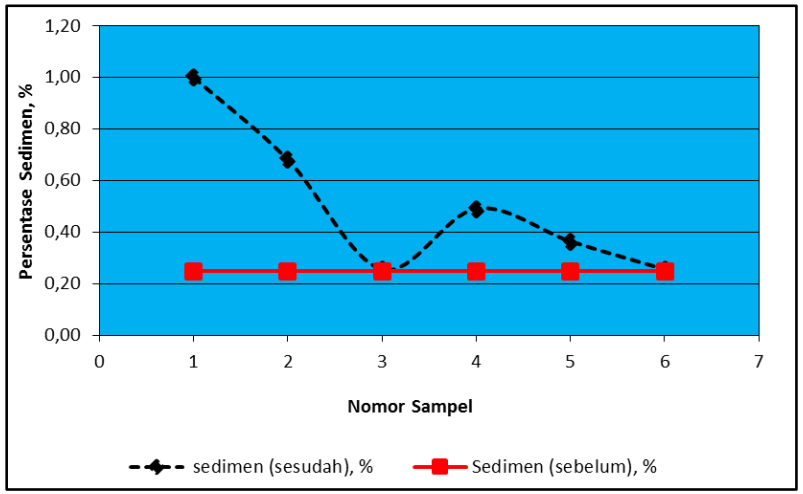

Gambar 3.3 Grafik Persentase Sedimen Sebelum dan Sesudah Filtrasi

Gambar 3.3 menunjukkan persentase kandungan sedimen pada air formasi sebelum dan sesudah dilakukan penyaringan. Persentase sedimen setelah dilakukan penyaringan menunjukkan hasil yang meningkat. Peningkatan ini diindikasikan bahwa batok kelapa yang digunakan sebagai filter pada proses penyaringan mengandung sedimen. Dari gambar 3.3 dapat dilihat bahwa sampel batok kelapa nomor 1 (halus) menunjukkan nilai sedimen yang paling besar yaitu $1 \%$. Persentase sedimen yang besar sangat dihindari dalam air formasi, sehingga sampel batok kelapa nomor 1 (halus) kurang tepat digunakan dalam peralatan yang sensitif terhadap sedimen. Sedangkan kandungan sedimen yang paling kecil berada pada sampel batok kelapa nomor 3 (kasar) dan nomor 6 (sedang kasar) dengan persentase 0,26\%. Hal ini dikarenakan sampel batok kelapa yang berukuran kasar lebih mudah untuk dibersihkan dari sedimen pada saat proses pencucian. Untuk peralatan yang sensitif terhadap kandungan sedimen maka disarankan untuk menggunakan sampel yang berukuran kasar (3) dan berukuran sedang kasar (6).

\subsubsection{Uji Kandungan Oil Content sebelum dan sesudah Filtrasi}

Pada gambar 3.4 menunjukkan persentase oil content sebelum dan sesudah penyaringan. Untuk persentase oil content awalnya semua berada diangka $12 \%$.

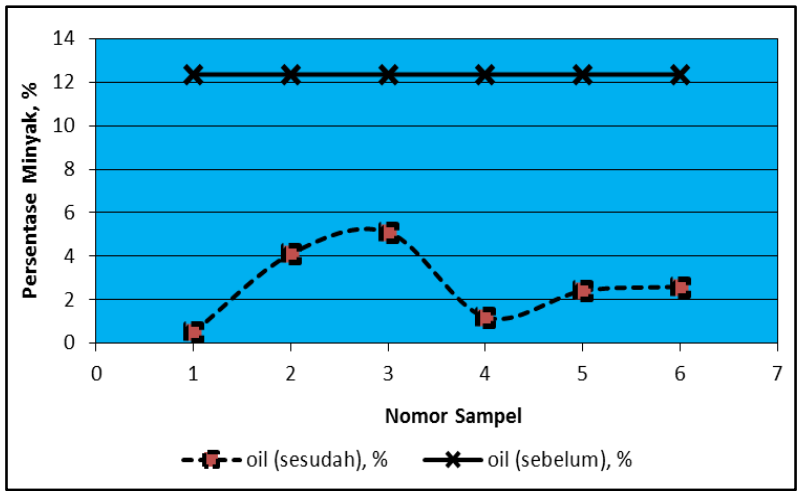

Gambar 3.4 Grafik Persentase Oil Content

Dari hasil penyaringan yang telah dilakukan, ukuran batok kelapa nomor 1 (halus) memberikan persentase hasil oil content terkecil yaitu sebesar $0,50 \%$ terhadap keseluruhan volume fluida yang tersaring. Persentase oil terbesar berada di angka 5,10\% dimiliki oleh sampel batok kelapa nomor 3 (kasar). hal ini mengindikasikan bahwa semakin kecil ukuran batok kelapa maka semakin bagus daya serapnya terhadap oil content. Pengkombinasian beberapa ukuran 
batok kelapa yang digunakan, yang6 ditunjukkan oleh sampel nomor 4 (halus sedang), 5 (halus kasar),dan 6 (sedang kasar) memberikan nilai persentase oil content yang dapat dijadikan sebagai alternative pemilihan selain sampel batok kelapa nomor 1 (halus) yang sebelumnya terindikasi mengandung banyak sedimen.

\subsection{Hasil Akhir Penelitian}

Untuk menentukan komposisi sampel dengan ukuran terbaik yang dapat dijadikan sebagai alternatif pengganti media filter pada cartridge filter maka dilakukan proses penilaian (scorring) pada tiap-tiap sampel. Dimana sistem penilaian yang dilakukan adalah dengan memberi nilai 6 untuk sampel terbaik dan nilai 1 untuk sampel terburuk dalam hasil analisis. Selengkapnya dapat dilihat pada tabel 3.4 sebagai berikut:

\section{Tabel 3.4 Penilaian Sampel Batok Kelapa}

\begin{tabular}{|c|l|c|c|c|c|c|c|}
\hline \multirow{2}{*}{$\dot{z}$} & \multirow{2}{*}{ Parameter } & \multicolumn{6}{|c|}{ Penilaian Sampel } \\
\cline { 3 - 8 } & $\begin{array}{c}1 \\
(\mathrm{H})\end{array}$ & $\begin{array}{c}2 \\
(\mathrm{~S})\end{array}$ & $\begin{array}{c}3 \\
(\mathrm{~K})\end{array}$ & $\begin{array}{c}4 \\
(\mathrm{HS})\end{array}$ & $\begin{array}{c}5 \\
(\mathrm{HK})\end{array}$ & $\begin{array}{c}6 \\
(\mathrm{SK})\end{array}$ \\
\hline 1 & Laju Alir & 1 & 3 & 6 & 2 & 4 & 5 \\
\hline 2 & $\begin{array}{l}\text { Kapasitas } \\
\text { Penyerapa } \\
\text { n }\end{array}$ & 6 & 4 & 1 & 5 & 3 & 2 \\
\hline 3 & $\begin{array}{l}\text { Jumlah } \\
\text { Sedimen }\end{array}$ & 1 & 2 & 6 & 3 & 4 & 6 \\
\hline 4 & Jumlah Oil & 6 & 2 & 1 & 5 & 4 & 3 \\
\hline \multicolumn{2}{|l}{ Total } & 14 & 11 & 14 & 15 & 15 & 16 \\
\hline
\end{tabular}

Dari hasil scorring di atas, dapat dilihat urutan sampel yang bisa dijadikan sebagai alternatif media filtrasi, yaitu :

1. Sampel nomor 6 dengan komposisi butiran sedang-kasar

2. Sampel nomor 4 dengan komposisi butiran halus-sedang

3. Sampel nomor 5 dengan komposisi butiran halus kasar

4. Sampel nomor 1 dengan komposisi butiran halus

5. Sampel nomor 3 dengan komposisi butiran kasar
Sampel nomor 2 dengan komposisi sedang

Dari total penilaian, sampel yang dianjurkan untuk digunakan sebagai media filtrasi adalah sampel nomor 6 dengan total 16 dengan komposisi butiran batok kelapa sedang-kasar.

\section{KESIMPULAN DAN SARAN \\ 5.1 Kesimpulan}

Dari penelitian mengenai penggunaan batok kelapa sebagai media alternatif dalam penggantian cartridge filtration pada proses pemisahan oil content dari air formasi, dapat ditarik kesimpulan:

1. Batok kelapa mempunyai daya ikat atau adsorbsi, sehingga bisa digunakan sebagai media filtrasi dalam pemisahan oil content.

2. Komposisi optimal batok kelapa yang dapat digunakan sebagai media filtrasi pada penelitian ini adalah kombinasi antara sedang-kasar dengan ukuran (3020) mesh.

\section{DAFTAR PUSTAKA}

Augustine Osamor Ifelebuegu and Zenebu Momoh. 2015. An Evaluation of the Adsorptive Properties of Coconut Husk for Oil Spill Cleanup. Proc. of the Intl. Conf. on Advances in Applied science and Environmental Technology - ASET. Copyright (C) Institute of Research Engineers and Doctors,. USA .All rights reserved. ISBN: 978-1-63248-040-8 doi: 10.15224/ 978-163248-040-8- 38. Hal 35-37.

Noor Al-Jammal, Tatjána Juzsakova. 2017. Review on the effectiveness of adsorbent materials in oil spills clean up. Proceedings of 7th International Conference of ICEEE, 17-19 of November 2016, Budapest, Hungary. Hal 131-138.

Neng Mastiani, Vina Amalia, Tina Dewi Rosahdi. 2018. Potensi Penggunaan Tempurung Kelapa sebagai Adsorben Ion Logam Fe(III). Jurnal Ilmu Kimia dan terapan Al-Kimiya. Volum 5 nomor 1. 
https://journal.uinsgd.ac.id/index.php/ak/articl e/view/3731. Diakses pada 15 April 2019.

Lucia Hermawati Rahayu, Sari Purnavita, Herman Yoseph Sriyana. 2014. Potensi sabut dan tempurung kelapa sebagai adsorben untuk meregenerasi minyak jelantah. Jurnal Ilmiah Momentum. Volum 10 nomor 1. https://publikasiilmiah.unwahas.ac.id/index.ph p/MOMENTUM/article/view/964. Diakses pada 15 April 2019

Alaert, G. 1987. Metoda Penelitian Air. Edisi 1 Airlangga Press, Surabaya. Peratura daerah provinsi Jawa Tengah, No. 10 Tahun 2014 tentang Baku Mutu Air Limbah BAPPEDAL

Nasruddin. 2005. Dynamic Modeling And Simulation Cycle Adsorption. Diosertation, Rwth.hal 3-12

Suhartana. 2007. Pemanfaatan Kelapa Sebagai Bahan Baku Arang Aktif Dan Aplikasinya Untuk Penjernihan Air Limbah Industri. Momentum, Vol. 3, No. 2. hal 10-15. 
P-ISSN: 2089-5925 E-ISSN: 2621-9328

Antrant

Jurnal Teknik Patra Akademika

PATA

LII I 